\title{
A domestic model for successful implementation of enterprise resource planning (ERP) systems in Iranian manufacturing enterprises
}

\author{
Mohammad Rahmani* and Mohammad Reza Taghva
}

Department of IT Management, University of Allameh Tabatabaee, Tehran, Iran

\begin{tabular}{|c|c|}
\hline A R T I C L E I N F O & A B S T RA C T \\
\hline $\begin{array}{l}\text { Article history: } \\
\text { Received July } 15,2011 \\
\text { Received in Revised form } \\
\text { September, } 12,2011 \\
\text { Accepted } 28 \text { September } 2011 \\
\text { Available online } \\
3 \text { October } 2011 \\
\text { Keywords: } \\
\text { Social architecture } \\
\text { ERP } \\
\text { Human behavioral }\end{array}$ & $\begin{array}{l}\text { This research investigates the human-behavioral dimension of technology acceptance in } \\
\text { enterprises. It is evident that accepting a technology depends on the underlying circumstances } \\
\text { of the environment. We have approached this issue from two different angles of social and } \\
\text { technological architecture. The research tries to explore proper enterprise architecture for ERP } \\
\text { system acceptance. Social Architecture (SA) is defined as the set of circumstances that makes } \\
\text { people behave in a particular way. So behavior of persons (employees of an enterprise) can be a } \\
\text { function of SA. Hence acceptance of a system can be dictated by SA and manipulating SA can } \\
\text { result in desirable success for a technology system. We have achieved various variables of } \\
\text { social architecture and have examined their relevance to system acceptance and success in } \\
\text { related enterprises (research domain) beside technological architecture variables . } \\
\text { The results have indicated that a special form of social and technological architecture can lead } \\
\text { to success for ERP system in the enterprises of the research domain. This gave us a model of } \\
\text { architecture. }\end{array}$ \\
\hline
\end{tabular}

\section{Introduction}

The primary objectives in technology adoption are national and cultural considerations. In addition, an important aspect of implementing enterprise resource planning (ERP) is the ease of implementation. While companies all over the world have heavily invested on the implementation of ERP, we have witnessed unexpected outcomes and a blurred realization of their final profit. There are many other issues when an ERP is considered but the following include the most important ones,

- Construction/Constitution of ERP (concentration on the processes of conceptualization and redefining work),

- ERP as an organizational circumstance (concentration on the sense-making of organizations and normative perspectives of ERP),

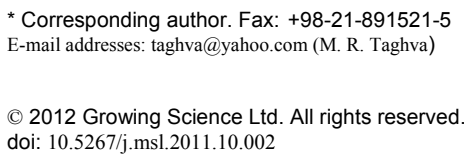


- Expected and unexpected outcomes of ERP (concentration on the globalization of organizations and power relations).

Based on the interaction of these three dimensions of ERP, cultural powers around this technology can be examined and it can be discovered that how this technology in turn affects organizational cultures. Many studies performed in the field of ERP tell us about gaps that are seen between the expectations and realities of ERP projects. Cultural processes demand a great deal of attention (Weick, 1995).

In studying the culture, the most important point is the most important factor, since the culture refers to the processes of sense-making and conceptualization, which takes place from a particular point of view. The actor's point of view can be understood through the "Life-world" approach. Meanwhile the life-world cannot be studied without considering the characteristics of ERP systems. It is important that how IT systems and life-world is associated with each other. This is because cultural relationships are reconstructed through development and deployment of ERP systems. The system and life-world should be seen as two important issues of an organization and the intermediary structures and organizations play important role. Based on the intermediary structures and roles in ERP, human and nonhuman actors can be differentiated (Callon et al. 1992).

Technological environments have considerable effects on organizational culture but are not its sole determinants. These environments form a technological culture to which managers and researchers should pay attention seriously. From management point of view, it is necessary to discern unique national background of a country in implementation of ERP. Early identification of the relationship between implementation of ERP and different national variables, create a true basis for budgeting implementation costs and make the possibility of proper planning of future executive actions.

Based on academic classifications, researches on the IT implementation can be classified in three areas: factors, process, and political research (Kwon \& Zmud, 1987). The process research investigates activities related to "social change" and claims the implementation succeeds once the commitment to the change and endeavor for implementation exists, a complete definition be made from the project, and process management is led by organizational change theories (Ginzberg, 1981; DeSanctis \& Poole, 1994). Implementing ERP encompasses a series of activities, each related to specific factors of organizational change, which are important in implementation success (Gupta, 2000; Willis \& Brown, 2002; Almashari, 2003). It should be noted that because of the costs and risk of changing a software package, the business process model in ERP projects should have required characteristics for congruence with it. Meanwhile may optimum business processes for an organization conflict a standard defined function. For implementation, it may be required that indices of objectives and performance defined by managers are modified and this may result in structures and activities that contradict the optimum functions and work flows (Gulla \& Brasethvik, 2002).

\subsection{Literature Review}

Jacobs and Whybark (2000) through a study on implementing "enterprise resource planning" in companies having facilities (branches) in multiple companies, demonstrated how implementing ERP in multinational facilities can result in catastrophe unless differences in culture of each company, production methods, and customer demand is considered. 
Markus et al. (2000) found the complexities of multisite implementation of ERP. When facilities are installed in different countries, national differences such as national culture, language, management style, political affairs, regulations, customs, etc. can affect the "way of doing business" (Hofstede, 1983; Simchi-Levi et al., 2000). Previous studies have led us to the point that these national differences affect different areas of information technology including technology transfer among different countries (Shore \& Venkatachalam, 1996), construction of global information infrastructure (Garfield \& Watson, 1998; Png et al., 2001), global information management (Lai, 2001), the role of information (Gallupe \& Tan, 1999), planning, global adoption and implementation of technology (Palvia et al., 2002) and other areas (Gallupe \& Tan, 1999; Palvia et al. 2002; Holland \& Light, 1999).

Another research that refers to Asian countries, Soh et al. (2000) studied ERP implementation activities in a hospital in Singapore and at the result, they warned about potential misfit in ERP implementation in Asia. In a research done in France with the title of "Evaluation of success of change through ERP; a case study of African ban of development", success of these changes has been studied from a "subjective measures" viewpoint. In this research, which has been done for the African bank of development as a case study, specifically the organizational dimension of ERP has been investigated in an organizational change perspective.

Worley and Hermosillo (2005) emphasized on the human resource characteristics in business processes and note that these characteristics are critical during acquisition and optimization stages of ERP. In this regard they articulate that the business processes should be adjusted with human actors in concepts such as the role, competency, and human knowledge. Through a case study implementation of PeopleSoft in a university, they demonstrated how these concepts could optimize ERP adoption and realize the objective of enhancing efficiency and system acceptance. Following figure represents result of their research.

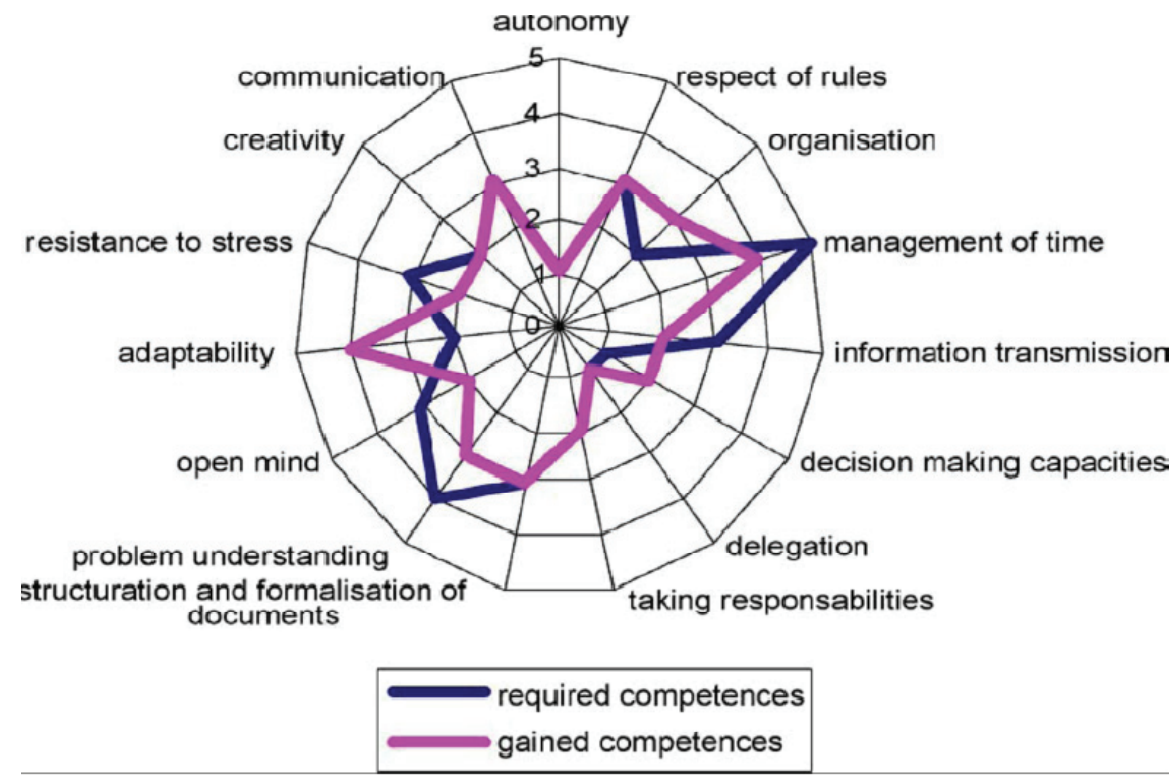

Fig. 1. Worely et al. research; Comparison of existing and required competencies for ERP 
Looking aggregately at the related previous research the importance of national and cultural differences and necessity of doing domestic research in specific countries is demonstrated. Examples of such domestic circumstances are as follow,

- Non written regulations,

- Considerable changes in managerial levels,

- Political considerations.

On the other hand, we witness huge companies invested on ERP but have confronted challenge in the way of implementation.

Hence, the issue where the current research tries to deal with is the incongruence between a technology and the context, which is decided to adopt. We take the ERP system technology and we investigate the context as "architecture" in which this technology is going to be implemented. This architecture includes social and technological architecture; enterprise architecture. Social architecture based on the above mentioned explanations is the focal point of this research. The research questions can be phrased as follows,

- Why ERP projects do not succeed (in considerable cases),

- Whether or not enterprise architecture is in congruence with this solution,

- What parameters the architecture in accordance with ERP must have,

- How this architecture can be identified,

- If this "proper" architecture is somehow identified - through the research methodology - and there was a gap between that and the current one, how will the road map through which the enterprise can be transformed to the proper architecture be?

\subsection{The complementary role of Structure and Technology}

The information technology is a substitute for organizational structure, since it provides information flows that previously took place through organizational hierarchy (Sauer \& Willcocks, 2003). This is important since the information technology and specially ERP can challenge the importance of structure through its integrative characteristic. Of course, this does not mean substitution of the structure; the importance of structure is in making complex arrangement controllable. According to Sauer and Willcocks (2003) the structure plays an important role for making a complex business more manageable and assuring about responsibility-taking.

Therefore, the technology and structure are complementary; structures create frontier and the technology makes it possible to cross these frontiers. In this way, complex business processes become manageable in a competent way (Sauer \& Willcocks, 2003).

The capability of crossing frontier through technology is focal to the ERP systems and work flow systems.

\subsection{Enterprise Architecture}

Organizational experts introduced the notion of enterprise from Delta consulting group in 1992. This notion contains:

- The formal structure, 
- The design of work activities,

- The nature of formal organization or operational style,

- The Processes of selection, socialization, and people development (ARIS, 2006).

\subsection{Efficiency and Flexibility Requirements; ERP \& EA}

When efficiency is to be realized in an operation, one should disregard flexibility. On the other hand, realization of variety (variance), is a prerequisite for flexibility. Hence it is very difficult to composite the advantages of big companies and strengths of small companies (Trinskjær, 2009). This requires a technological base, which integrates distribution and centralization. It seems that integrating efficiency and flexibility will be dominant challenge of business in near future. Business models change more than one time a year and new processes should be implemented in few months or even some weeks.

According to Prahalad and Krishnan (2008) efficiency and flexibility are not contradictory. However, for having both of these, one should change new principal play rule of the competitive domain: Globalization of resources and customer entity - the core of value creation.

\section{Role of Management; Social Architecture}

According to Trinskjær (2009) social architecture can be defined as "set of systems, processes, beliefs, and values that determine the behavior, viewpoints, and skills of an individual in the organization".

We've finalized four variables for the social architecture, which would be presented in our research model bellow.

\section{Role of Tool; Technological Architecture}

Since future architecture requires both efficiency and flexibility together, this is debatable for technological architecture as well as social architecture.

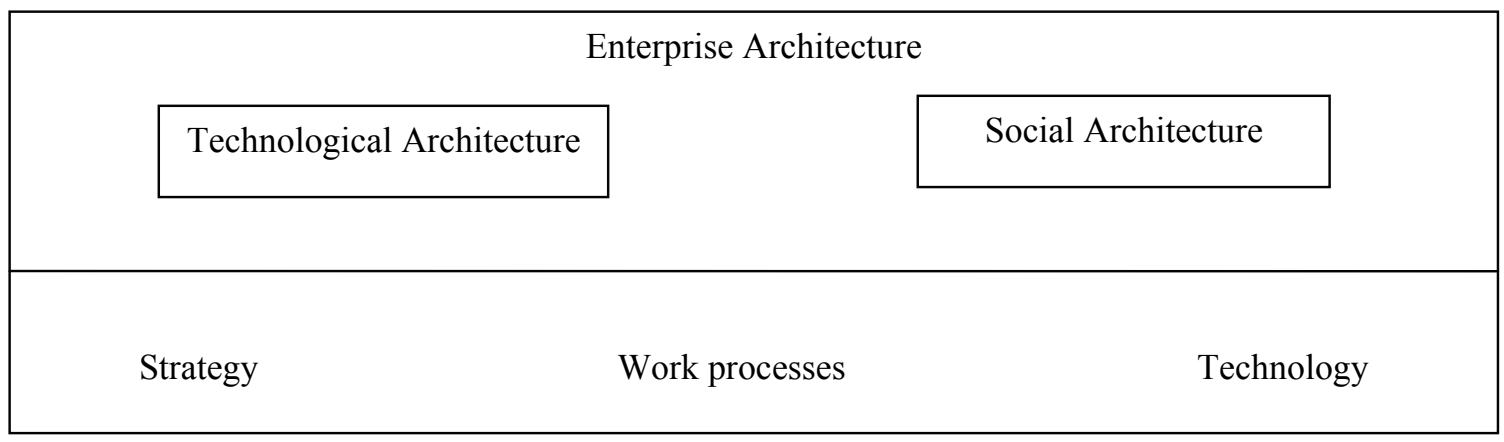

Fig. 2. Enterprise Architecture Components

As it is shown in Fig. 2, the architecture can be figured out in the frame of social and technological architecture. Enterprise architecture is an approach through which one can envisage technology. ERP is a technology, which has a highlighted role in technology architecture. 


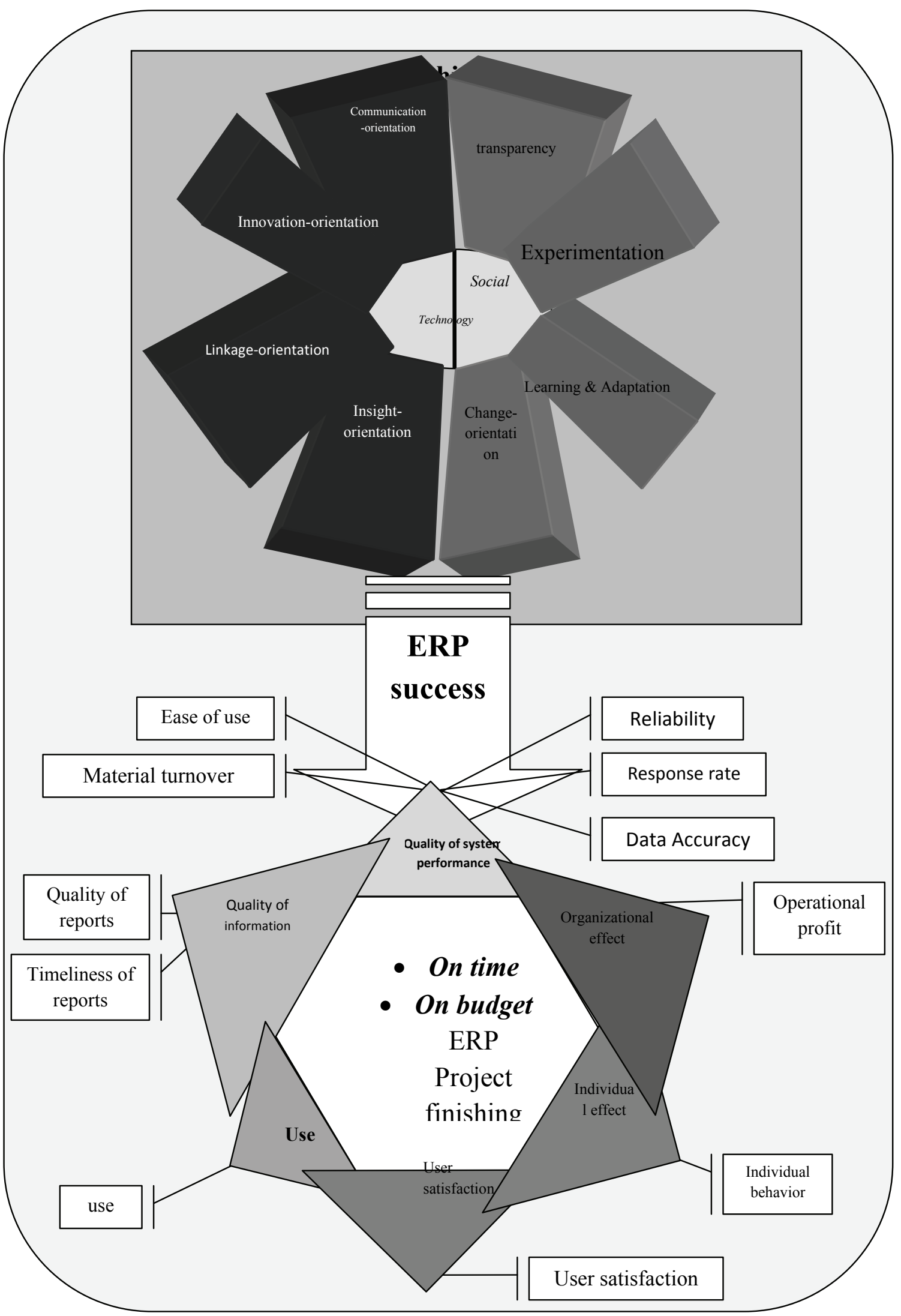

Fig. 3. Research model 


\section{Methodology}

This research was done in domain of those Iranian manufacturing enterprises, which had initiated acquisition of ERP system. The research method is explanatory research method. Research type is correlation analysis. The population in this research is limited in the domain and practically the sample number is equal to the population. Data gathering tool in this research is questionnaires and its validity is verified by experts and its reliability is calculated through Cronbach's alpha criteria. After gathering data through questionnaires, various analyses are done through the statistical analytical tools of SPSS and Excel. Statistical techniques showed that Learning/adaptability, Experimentation, and Innovation-orientation have correlations with the dependent variable, ERP success. Transparency, change-orientation, communication-orientation, linkage-orientation, and insight do not show a significant correlation with the dependent variable. However, in the regression model of ERP success function, intervention of all of these variables is significant.

\section{Analysis results}

\subsection{Correlations analyses}

Transparency \& ERP success: significance level of the test is more than 0.50 so there is no significant relationship between transparency and ERP success.

Experimentation and ERP success: significance level of the test is less than 0.50 so there is a significant relationship between experimentation and ERP success. Correlation coefficient is -0.189 . Hence experimentation has a reverse correlation and not so much powerful.

Learning/adaptation and ERP success: significance level of the test is more than 0.50 , so there is a significant relationship between adaptation and ERP success. Correlation coefficient is calculates as 0.486 showing that this correlation is direct and relatively strong.

Change-orientation and ERP success: significance level is more than 0.50, so there is not a significant correlation between two variables of change-orientation and ERP success.

Communication-orientation and ERP success: significance level of the test is more than 0.50, so a significant relationship doesn't exist between these two variables.

Innovation-orientation and ERP success: Significance level is less than 0.50 , so there is a significant relationship between innovation-orientation and ERP success. Correlation coefficient is calculated as "-0.168". Hence, the correlation coefficient is reverse.

Linkage-orientation and ERP success: Significance level of the test is 0.50, so there is not a significant relationship between linkage-orientation and ERP success.

Insight-orientation and ERP success: Significance level of the test is more than 0.50 , so a significant relationship doesn't exist between Insight-orientation and ERP success.

\subsection{Regression analysis}

Regression analysis with ERP success as dependent variable and transparency, experimentation, learning/adaptation, change-orientation, communication-orientation, innovation-orientation, linkageorientation, and insight-orientation as autonomous variables was performed. In a stage-wise 
regression method used, as is shown in Table 1, the Learning/adaptation was entered first. Then Transparency and then Innovation-orientation, Change-orientation, Insight-orientation, Linkageorientation, and Communication-orientation were entered, retrospectively. Eight models were achieved through this method. The first model included one sole variable of "Learning/adaptation", the second model included two variables of "Learning/adaptation" and "Transparency", the third one, included three variables of "Learning/adaptation", "Transparency", and "Innovation-orientation", and so on till the eighth model. The eight models included all of the variables.

\section{Table 1}

Variables Entered/Removed(a)

\begin{tabular}{lll}
\hline Model & Variables Entered & \multicolumn{1}{c}{ Method } \\
\hline 1 & Learning/ adaptation & Stepwise (Criteria: Probability-of-F-to-enter $<=.050$, Probability-of-F-to-remove $>=.100)$ \\
2 & Transparency & Stepwise (Criteria: Probability-of-F-to-enter $<=.050$, Probability-of-F-to-remove $>=.100$ ) \\
3 & Innovation orientation & Stepwise (Criteria: Probability-of-F-to-enter $<=.050$, Probability-of-F-to-remove $>=.100$ ) \\
4 & Experimentation & Stepwise (Criteria: Probability-of-F-to-enter $<=.050$, Probability-of-F-to-remove $>=.100$ ) \\
5 & Change-orientation & Stepwise (Criteria: Probability-of-F-to-enter $<=.050$, Probability-of-F-to-remove $>=.100$ ) \\
6 & Insight-orientation & Stepwise (Criteria: Probability-of-F-to-enter $<=.050$, Probability-of-F-to-remove $>=.100$ ) \\
7 & Linkage-orientation & Stepwise (Criteria: Probability-of-F-to-enter $<=.050$, Probability-of-F-to-remove $>=.100$ ) \\
8 & $\begin{array}{l}\text { Communication- } \\
\text { orientation }\end{array}$ & Stepwise (Criteria: Probability-of-F-to-enter $<=.050$, Probability-of-F-to-remove $>=.100$ ) \\
&
\end{tabular}

Following model obtained based on the coefficients Table:

ERP Success $=7 / 204+(-0 / 911) *$ Transparency $+(0 / 981) *$ Experimentation $(1 / 844+) *$ Learning/adaptation $+(-1 / 102) *$ Change-orientation +

$(-0 / 334) *$ Communication-orientation $+(-1 / 393) *$ Innovation-orientation $+(-0 / 282) * \quad$ Linkage-orientation $+(-0 / 326) *$ Insight-orientation

Accuracy of the model

Table 2 represents a model summary used for investigating the accuracy of obtained models;

Table 2

Model Summary

\begin{tabular}{ccccc}
\hline Model & $\mathrm{R}$ & $\mathrm{R}$ Square & Adjusted R Square & Std. Error of the Estimate \\
\hline 1 & $.504(\mathrm{a})$ & .254 & $\mathbf{. 2 4 8}$ & .71808 \\
2 & $.593(\mathrm{~b})$ & .352 & $\mathbf{. 3 4 1}$ & .67213 \\
3 & $.615(\mathrm{c})$ & .379 & $\mathbf{3 6 3}$ & .66072 \\
4 & $.672(\mathrm{~d})$ & .452 & $\mathbf{. 4 3 4}$ & .62290 \\
5 & $.765(\mathrm{e})$ & .585 & $\mathbf{. 5 6 8}$ & .54463 \\
6 & $.782(\mathrm{f})$ & .612 & $\mathbf{. 5 9 3}$ & .52850 \\
7 & $.792(\mathrm{~g})$ & .628 & $\mathbf{. 6 0 6}$ & .51995 \\
8 & $.804(\mathrm{~h})$ & .646 & $\mathbf{. 6 2 2}$ & .50912 \\
\hline
\end{tabular}

a Predictors: (Constant), learning and adaptation

b Predictors: (Constant), learning and adaptation, transparency

c Predictors: (Constant), learning and adaptation, transparency, innovation

d Predictors: (Constant), learning and adaptation, transparency, innovation, experimentation

e Predictors: (Constant), learning and adaptation, transparency, innovation, experimentation

f Predictors: (Constant), learning and adaptation, transparency, innovation, experimentation, insight

g Predictors: (Constant), learning and adaptation, transparency, innovation, experimentation, insight, linkage

$\mathrm{h}$ Predictors: (Constant), learning and adaptation, , transparency, innovation, experimentation, insight, linkage, communication

Based on the last model, we conclude that all of the defined variables have significance level of bellow 0.50. Therefore, the set of these variables have capability of explaining the dependent variable. Results obtained by Pierson correlation analysis and the regression method, raise this question that why through the correlation method just three variables show relationship with the ERP success, while regression analysis demonstrates significant relation of all the variables? A correlation analysis was performed between autonomous variables by a next stage; result disclosed that there was 
significant relationship between variables that have correlation relation with ERP success and other variables; because of this relationship, other variables such as Transparency, Change-orientation, Communication-orientation, Linkage-orientation, and Insight-orientation affect ERP success in an indirect manner. This finding is a general estimation. Precise understanding of this and discovering cause-and-effect relationships in this regard by itself requires an autonomous research. This will be one of future research proposing of the research.

A general conclusion is:

Experimentation, Learning/adaptation, and Innovation-orientation show an effect on ERP successwithout any intermediate variable - but Transparency, Change-orientation, Communicationorientation, Linkage-orientation, and Insight-orientation have effect on ERP success via some intermediates. From a practical perspective, this can be explained in an enterprise architecture dynamics: eight variables considered in this research for enterprise architecture dimensions, together show a special pattern of effect on ERP performance, while considering these effects separately, we have achieved another form of effect. Based on a system approach, therefore, aggregate effect of architecture variables means a systematic relationship between them that together form enterprise architecture figure.

Possibly management culture transparency don't have an autonomous correlation with ERP success, but once the Transparency realize beside Learning/adaptation feature in enterprise social architecture, the result will be a higher score of ERP success. In this way, systematic relation and synergy between dimensions of architecture become clear. This relation in a higher level exists between Social Architecture and Technology Architecture.

Per the regression analysis, Learning/adaptation variable has the most important effect in the model with a Beta coefficient of "0.945". Innovation has a reverse correlation (coefficient of -0.802) and Experimentation with a coefficient equal to " 0.8 " has a direct correlation. Change-orientation is in fourth rank with a coefficient of "-0.539", Transparency in fifth rank, Insight in sixth with coefficient of "-0.259", Communication-orientation is in seventh, and Linkage-orientation with a coefficient of "$0.171 "$ takes the eighth rank. All of the aforementioned items are displayed through the following table:

Table 3

Absolute standard coefficient

\begin{tabular}{ccc}
\hline Variable & $\begin{array}{c}\text { Absolute standard } \\
\text { coefficient }\end{array}$ & Rank \\
\hline Learning/adaptation & 0.945 & 1 \\
Innovation-orientation & 0.802 & 2 \\
Experimentation & 0.8 & 3 \\
Change-orientation & 0.539 & 4 \\
Transparency & 0.512 & 5 \\
Insight-orientation & 0.259 & 6 \\
Communication-orientation & 0.211 & 7 \\
Linkage-orientation & 0.171 & 8 \\
\hline
\end{tabular}


Table 4

Runs Test

\begin{tabular}{cc}
\hline Non standardized Residual & \\
\hline-.06564 & Test Value (Median) \\
64 & Cases $<$ Test value \\
64 & Cases $>=$ Test value \\
128 & Total cases \\
65 & Number of runs \\
.000 & $Z$ \\
1.000 & Asysmp. Sig. (2-tailed) \\
\hline
\end{tabular}

We concluded that since our obtained model meets three conditions of Normality, fixed variance, and Independency, so results are reliable.

Results obtained from analyzing correlations between independent variables and efficiency criteria

Hereby we present the analysis of the correlations between architecture variables and two efficiency variables; Timeliness and Cost of ERP project. We have some of the statistical analyses results in this regard, which are summarized in Table 5.

Table 5

Test Statistics(a,b)

\begin{tabular}{|c|c|c|c|c|c|c|c|c|}
\hline Feature & Transparency & Experimentation & Adaptability & Changeability & $\begin{array}{l}\text { Communication- } \\
\text { orientation }\end{array}$ & $\begin{array}{l}\text { Innovation- } \\
\text { orientation }\end{array}$ & $\begin{array}{l}\text { Linkage- } \\
\text { orientation }\end{array}$ & $\begin{array}{l}\text { Insight- } \\
\text { orientation }\end{array}$ \\
\hline Chi-Squre & 12.750 & 14.778 & 14.778 & 15.002 & 14.50 & 16.750 & 13.25 & 18.250 \\
\hline Df & 3 & 3 & 3 & 3 & 3 & 3 & 3 & 3 \\
\hline $\begin{array}{l}\text { Asymp. } \\
\text { Sig. }\end{array}$ & 0.005 & 0.002 & 0.002 & 0.002 & 0.002 & 0.001 & 0.003 & 0.000 \\
\hline
\end{tabular}

Based on analysis results, effect of ERP on data accuracy was $65 \%$, Reports Timeliness $63 \%$, Reports Quality comparing legacy system $62 \%$, Reliability $57 \%$, Ease of use $57 \%$, Use of the system comparing legacy system $57 \%$, Lead time reduction $56 \%$, Response rate $56 \%$, Inventory turnover $51 \%$, User satisfaction comparing legacy system $49 \%$, Material shortage decrease $47 \%$, Individual behavior quality $43 \%$, and On time product delivery $41 \%$. Organizational performance regarding operational profit or other similar criteria and Material consumption decrease show $40 \%$ and $35 \%$ of response, retrospectively.

\section{Conclusions}

ERP can be regarded as a general approach for managing huge areas. On the other hand, ERP systems encompass any business process that can be imagined. Meanwhile many studies have been done on the general flexibility of ERP systems after configuration. The last generation of ERP systems provides a "Service-oriented Architecture" which brings flexibility.

The strategic role of ERP systems in technology architecture as well as social architecture is considerable. This point is important that technology under use should support future requirements of an enterprise. ERP as a considerable part of technology architecture and social architecture as well, requires rethinking so that realizes efficiency and flexibility requirements. ERP providers confront some challenges in this way. 
Actually once efficiency requirements come to the field, most of these requirements are covered through current ERP solutions: the dream of bringing automation to business processes is a main motive for deploying ERP systems. For this aim ERP systems provide ascertained best-practice processes so that decrease fluctuations and control variations.

Some of flexibility requirements of future technology architecture can be realized through today's ERP technology. ERP II encompasses external domain also, as it is raised in ERP maturity model. This provides the possibility of external integration as well as internal integration. If, as Prahalad and Krishnan forecast, future competitive environment move toward globalization, then organizations which use updated ERP, will have good preparedness.

\section{Further research}

In this research, we have investigated proper enterprise architecture for successful ERP system implementation. Now this question may arise that if this architecture will be proper for an enterprise from other aspects or not, and can approaching to this architecture - that prepares the enterprise for ERP - will be in accordance with other objectives and strategic directions and commitments of the enterprise or not? Response to this question requires a comprehensive analysis of the enterprise from internal and external views and trend analyses. This is proposed as a future research design.

Independent variables in this research showed significant correlations; so that each variable affect the dependent variable through another variable. Variables that have significant correlation with dependent variable, play an intermediary role and cause other variables which otherwise have no significant correlation with dependent variable, enter in the model. A proposed research thus is to; discover causal relationships between independent variables of this research (architecture variables) and identification and explanation of them.

This research will be extended to a wider domain with a new concept of "Social Architecture" and "Human Behavior" analyzing competence flourishing and employment.

\section{References}

Al-Mashari, M. (2003). Enterprise resource planning systems: a research agenda. Industrial Management \& Data Systems, 103(1), 22-7.

Cronbach, L. J. (1951). Coefficient alpha and the internal structure of tests. Psychometrika, 16(3), 297-334.

Gupta, A. (2000). Enterprise resource planning: the emerging organizational value systems. Industrial Management \& Data Systems, 100(3), 114-118.

Gallupe R.B, \& Tan, F.B. (1999). A research manifesto for global information management. Journal of Global Information Management, 7(3), 5-18.

Garfield, M.J., \& Watson, R.T. (1998). Differences in National Information Infrastructures: The Reflection of National Cultures. Journal of Strategic Information Systems, 6(4), 313-337.

Gulla, J. A., \& Brasethvik, T. (2002). A model-driven ERP environment with search facilities. Data \& Knowledge Engineering, 42, 327-341.

Hofstede G. (1983). The cultural relativity of organizational practices and theories. Journal of International Business Studies; 14(2), 75-89.

Holland, C.P., \& Light, B. (1999). Global enterprise resource planning implementation. Proceedings of the 32nd Hawaii International Conferences on System Sciences.

Lai, V. (2001). Issues of international information systems management: a perspective of ciliates. Information and Management, 38, 253-264. 
Lynne, M.M., Tanis, C., \& van Fenema, P. C. (2000). Multisite ERP Implementations. Communications of the ACM, 43, 4, 42-46.

Palvia, P.C., Palvia, S., \& Whitworth, J. (2002). Global information technology: a meta analysis of key issues. Information and Management, 39, 403-414.

Prahalad, C.K., \& Krishnan, M.S. (2008). The New Age of Innovation. New York, NY: McGraw-Hill. ISBN: 978-0-07-159828-6

Shore, B., \& Venkatachalam, A.R. (1996). Role of national culture in the transfer of information technology. Journal of Strategic Information Systems, 5, 19-35.

Simchi-Levi, D., Kaminsky, P., \& Simchi-Levi, E. (2000). Designing and managing the supply chain: concepts, strategies and case studies. Boston, MA: Irwin/McGraw-Hill.

Soh, C, Kien, S.S., \& Tay-Yap, J. (2000). Cultural fits and Misfits: is ERP a universal solution? Communications of the ACM, 43(3), 47-51.

Trinskjær, J. K. (2009). Combining Enterprise Architecture and ERP Systems, Master's thesis, the IT University of Copenhagen.

Willis, T., \& Brown, A. (2002). Extending the Value of ERP. Industrial Management \& Data Systems, 102(1), 35-38.

Worley, J.H., Chatha, K.A., Weston, R.H., Aguirre, O., \& Grabot, B. (2005). Implementation and optimisation of ERP systems: A better integration of processes, roles, knowledge and user competencies. Computers in Industry, 56(6), 620-638. 